Narrative Change in Emotion-Focused Therapy 1

This archive is a final draft of the paper. Please see the published final edited version as:

Mendes, I., Ribeiro, A., Angus, L., Greenberg, L., Sousa, I., \& Gonçalves, M., (2010). Narrative change in emotion-focused therapy: How is change constructed through the lens of the Innovative Moments Coding System? Psychotherapy Research, 20, 692-701. DOI:10.1080/10503307.2010.514960

http://www.tandfonline.com/doi/abs/10.1080/10503307.2010.514960 


\begin{abstract}
Aim: To apply a narrative methodological tool for the study of the change process in Emotion-Focused Therapy (EFT), replicating a previous study done with Narrative Therapy (NT). Method: The Innovative Moments Coding System (IMCS) was applied to 3 good and 3 poor outcome cases in EFT for depression to track the Innovative Moments (IMs) in the therapeutic conversation which are exceptions to the problematic self-narrative. IMCS allows tracking 5 types of IMs events: action, reflection, protest, re-conceptualization, and performing change. Results: The analysis revealed significant differences between the good and poor outcome groups regarding reconceptualization and performing change IMs, which replicates the findings from a previous study. Conclusions: Re-conceptualization and performing change IMs seem to be vital in the change process.
\end{abstract}




\section{Narrative Change in Emotion-Focused Therapy: How is change constructed through the lens of the Innovative Moments Coding System?}

Increasingly, the field of psychotherapy research has begun to address the fundamental question of how do clients construct their own process of change in effective therapy sessions. The present study aims to address this question by intensively analyzing events that facilitate the construction of new meanings, designated as Innovative Moments (or IMs, also designated in previous publications as i-moment) (Gonçalves, Matos, \& Santos, 2009; Gonçalves, Ribeiro, Matos, Santos, \& Mendes, in press; Matos, Santos, Gonçalves, \& Martins, 2009).

According to the narrative framework human beings give meaning to their life events through the narration of themselves, the others and the world (see Angus \& McLeod, 2004; McAdams, 1993; Sarbin, 1986; White \& Epston, 1990). The notion of IMs was inspired in White and Epston's (1990) concept of unique outcomes, defined as exceptions towards a problematic self-narrative. Thus, IMs are all the events in therapy in which the client describes or narrates him or herself differently than one would expect from the perspective of the problematic self-narrative that brought him or her into therapy. These can emerge in different forms, as a thought, a plan, a feeling, an action; that falls outside the influence of the rules of the problematic self-narrative that organizes the client's life. If the problematic self-narrative is the rule (e.g. lack of assertiveness - "He'll (husband) raise his voice and I simmer down and either walk away, or just forget about what was said and I don't fight it out."), then IMs are all the exceptions to this rule; all those times that the clients experiences and narrates something that, implicitly or explicitly, challenges or rejects the problematic self- 
narrative that has been shaping his or her life (e.g." I am me and these feelings belong to me, and if I want to tell him (husband) I will.").

Through the study of IMs we can track when the first signs of client therapeutic change are taking place and how they develop into a new narrative of the self emerging during the therapeutic process. This research studies how IMs develop in EmotionFocused Therapy (EFT), replicating a previous research from Matos et al. (2009) that analyzed how IMs developed in Narrative Therapy (NT) with women who were victims of intimate violence. In NT the therapist deliberately tries to elicited IMs, so one central question of the present research is if this concept could be used outside its context of origin and provides a picture of the narrative change in a therapy that is not focused on narrative constructs, more specifically on exceptions to the problem.

\section{Innovative Moments Coding System}

The Innovative Moments Coding System (IMCS) (Gonçalves, Ribeiro, et al., in press) provides a systematic, reliable method for the identification of IMs. IMCS allows the identification of five different types of IMs - action, reflection, protest, reconceptualization and performing change (see Table 1).

1. Action IMs are new accomplishments, specific actions that are different from what the problem impels the person to do.

2. Reflection IMs refer to new ways of thinking, feeling and new understandings about the implications of the problem in the clients' life that allow for the client to defy the demands of the problematic self-narrative.

3. Protest IMs entail new behaviors (like action IMs) and/or new thoughts (like reflection IMs) against the problem, representing a refusal of its assumptions. 
This active refusal is the key feature that allows distinguishing protest from action and reflection.

4. Re-conceptualization IMs are a more complex and multifaceted type of IM that enables the clients' comprehension about what is different about themselves and the process that fostered this transformation. These IMs require the clients' description of three components: the self in the past (problematic self-narrative), the self in present and the depiction of the process that allowed for this change.

5. Performing Changes IMs represent the performance of change, new ways of acting and being that emerge from the occurrence of the change process. They represent a process of transforming in-therapy outcomes into extra-therapy changes.

In a recent process-outcome study conducted by Matos et al. (2009), 10 women undergoing NT (White \& Epston, 1990) and who had been victims of intimate violence, were analyzed with IMCS. The results indicated that IMs appeared in both good $(\mathrm{N}=5)$ and poor $(\mathrm{N}=5)$ outcome cases. However, NT clients in the good outcome group were found to spend significantly more time in the sessions elaborating IMs. These overall differences were primarily due to differences in re-conceptualization and performing change IMs. No significant differences were found in action, reflection and protest IMs. From these results, and several intensive case-studies, using quantitative, qualitative and mixed designs (Gonçalves, Mendes, Ribeiro, Angus, \& Greenberg, in press; Ribeiro, Gonçalves, \& Ribeiro, 2009; Santos, Gonçalves, \& Matos, 2010; Santos, Gonçalves, Matos, \& Salvatore, 2009), it was hypothesized that re-conceptualization and performing change IMs may be necessary for the client self-narrative change to occur.

\section{Heuristic Model of Therapeutic Change}


On the basis of findings emerging from the studies detailed above, a heuristic model of narrative change was developed (Gonçalves, Matos, et. al, 2009; Matos et. al, 2009) which is summarized below.

In the first stage of therapy, action and reflection are usually the first IMs types to occur (see Figure 1). Action and reflection IMs are considered the most elementary forms of innovation, constituting signs to the self (and significant others) that distinct ways of acting, thinking and feeling are emerging in the client's life. Protest IMs may emerge after several cycles of action and reflection IMs and they can also occur in early therapy sessions. Protest IMs may emerge as an action or as a thought but either way they represent a more empowered position of the self towards the problematic selfnarrative, implying a strong attitudinal movement against the problem's dominance of the client's life. Although these three types of IMs represent important new ways of clients experiencing and understanding their problematic self-narrative, they appear to be insufficient for the development of a stable new self-narrative.

In contrast, re-conceptualization IMs appear to be crucial for the construction of a new self-narrative as they represent the integration of the client's new view of self in the context of the problematic self-narrative. The emergence of this new vantage point on self, as the author of one's own self story, also involves a form of meta-reflection or meta-cognition (Dimaggio, 2006). We suggest that re-conceptualization IMs organize and give coherence to the diversity of action, reflection or protest IMs, heightening the narrative structure vital when forging a new story (see Baerger \& McAdams, 1999). Thus, through re-conceptualization the client is not only able to integrate past with present and to assume an authoring position (given his or her access to the process of change), but can also give meaning and order to the more episodic innovations that emerge in the form of action, reflection and protest IMs. After the emergence of re- 
conceptualization new cycles of action, reflection and protest IM occur and validate the former re-conceptualization IMs. That is, as the client views him or herself different than before (re-conceptualization IMs) the further emergence of action, reflection and protest IMs, that are congruent with this re-conceptualization, provide further validation that significant change is taking place. Performing change IMs are the portrayal of this new self in several domains of the clients' daily and future life, and they can entail the engagement in new projects, new relationships and new activities.

Finally, the model suggests that it is the articulation of this new gestalt of reconceptualization IMs that allows for the emergence of a new self-narrative. In essence, a new set of rules that guide actions, thoughts, feelings and ways of relate to others that are incoherent with the problematic self-narrative that brought the client to therapy in the first place.

\section{Present Study}

The main goal of the present study is to investigate the emergence of IMs in EFT (Greenberg \& Watson, 1998) using the IMCS (Gonçalves et al., 2009; Gonçalves, Ribeiro, et al., in press). Since IMCS was inspired in NT (White \& Epston, 1990) this study is also a test of IMCS' applicability to other therapeutic modalities. If applicable, then the study of the IMs with a different clinical population (major depression instead of women victims of intimate violence) and in the context of other therapeutic models, will raise new exploratory research questions:

1. Can the IMCS reliably identify IMs types in EFT?

2. Do good outcome EFT cases present a higher proportion of IMs' than the poor outcome cases; as occurred in NT? 
3. Also as occurred in NT, do re-conceptualization and performing change IMs types occur more frequently and with more elaboration in good outcome cases than poor outcome cases?

4. Do the patterns of occurrence of IMs types that emerge across EFT sessions converge with the heuristic model of change drawn from NT? Specifically, do reconceptualization and performing change IMs increase along treatment?

\section{Method}

\section{Clients}

Clients participated in the York I Depression Study (Greenberg \& Watson, 1998), a project designed to assess treatments of major depression comparing 17 processexperiential (also referred as EFT) and 17 Client-Centered Therapy (CCT) treatments. In this study the clients were randomly assigned to one of the two different treatments (EFT or CCT). We studied 6 out of 17 cases assigned to EFT, which had 16 to 20 sessions of individual psychotherapy once a week. These 6 cases were the ones with complete transcripts for intensive process analyses.

Of the six clients in this sample four were women and two were men (age range = 27-63 years, $M=45.50$ years, $S D=13.78)$. Clients completed an average of $17.50(S D$ $=1.87)$ sessions. Five of the clients were married and one was divorced.

Clients were classified as having good or poor outcome based on the analysis of the Beck Depression Inventory (BDI; Beck, Steer, \& Garbin, 1988; Beck, Ward, Mendelson, Mock, \& Erbaugh, 1961) pre- to post-test change scores. BDI is a wellknown 21 item self-report instrument to assess symptoms of depression.

A Reliable Change Index (RCI) analysis of BDI pre- to post-test change scores classified three clients as having met criteria for recovered (i.e., passed both a BDI cut- 
off score of 11.08 and RCI criteria) and the other three clients were classified as unchanged (i.e., have not passed both BDI cut-off score of 11.08 and RCI criteria) at treatment termination (see Jacobson \& Truax, 1991; McGlinchey, Atkins, \& Jacobson, 2002). More specifically, pre-post BDI scores for the good outcome cases were 25 to 3 , 30 to 5 , and 35 to 4 , whereas for the poor outcome cases was 15 to 13,23 to 22 , and 24 to 18 .

\section{Therapists}

Five therapists conducted the therapeutic process of the six clients analyzed in this study. Four of the therapists were female and one was male. They were of varied levels of education, from advanced doctoral students in clinical psychology to $\mathrm{PhD}$ clinical psychologists. Four of the therapists were of Caucasian origin and one was Indian. All therapists received a 24 week training according to the manual devised for the York I Depression study (Greenberg, Rice \& Elliott, 1993). The received training consisted of eight weeks of CCT, six weeks for systematic evocative unfolding, six weeks for twochair dialogue and four weeks for empty-chair dialogue.

\section{Treatment}

The emotion-focused therapists assume the client-centered relational conditions and use experiential and gestalt interventions to facilitate the resolution of maladaptive affective-cognitive processing. These interventions included focusing (Gendlin, 1981) at a marker of an unclear felt sense, systematic evocative unfolding for problematic reactions, two-chair dialogue for self-evaluative and self-interruptive conflict splits and empty-chair dialogue for unfinished business with a significant other (Elliott, Watson, Goldman \& Greenberg, 2004; Greenberg, et al., 1993; Greenberg and Watson, 2006).

\section{Measures}


Innovative Moments Coding System

To study the process of change, the cases were coded using the Innovative Moments Coding System (IMCS, Gonçalves, Ribeiro, et al., in press). Table 1 describes how IMs are identified and give examples of the diversity in each type. Studies using IMCS showed a good reliability of the coding system, across therapeutic models and diagnoses (or problems). The average percentage of agreement ranged from $84 \%$ to $94 \%$ and the average Cohen's Kappa ranged from .80 to .97 , showing a strong agreement between judges (Hill \& Lambert, 2004).

\section{Procedures}

For the present study, the IMCS was applied to all session transcripts of 6 EFT cases selected from York I Project on Depression Study (Greenberg \& Watson, 1998).

All session transcripts from the two outcome groups - three good and three poor outcome cases - were intensively analyzed regarding the emergence of IMs and the specific types of IMs for each session of each case. Therefore, 105 sessions were coded in which 49 sessions fit into the good outcome group and 56 sessions belong to the poor outcome group. The sessions were coded from the transcripts of the cases.

The IMCS coding procedure required data analysis by two raters (first and second authors), that were unaware of the outcome status of the cases. The rater 1 (first author) coded the entire sample and rater 2 (second author) independently coded $50 \%$ of the sample sessions (53 sessions). The raters were trained by the authors of the manual (last author). Training included discussing the manual with the authors, coding transcripts from different samples, discussing disagreements and misunderstandings in the process of coding until a consensus was established. At the end of the training period reliability of raters was assessed by comparing their codes with the codes of 
expert judges in a set of randomly selected excerpts of dialogues of therapeutic sessions. Raters were considered to be reliable and able to engage in coding research material once they achieved a Cohen's Kappa higher than .75.

Three steps were carried out in the process of coding IMs: (1) A consensual definition of the problems by the two raters, (2) identification of each IM, defining its beginning and end, (3) categorization of previously identified IMs in terms of type and definition of its salience.

Consensual definition of problematic self-narratives by the two raters. The first step of the process of coding therapy sessions involved a careful reading of all psychotherapeutic transcripts. Following this initial procedure, raters independently listed the clients' problems (or themes of the problematic self-narrative), then met and discussed their understanding of what comprised each client's problematic selfnarrative. After this discussion, the problems were identified and consensually defined (as close as possible to the client's discourse). To make this procedure clearer we give an example of problematic narrative identified in the case of Lisa, a well-known EFT client from the York I Depression Study sample ("The Case of Lisa", 2008; Gonçalves, Mendes, et al., in press). One of Lisa's problematic self-narrative themes was "Resentment and difficulty in expressing her own feelings":

L: ... maybe that's why I don't tell him (husband) how I really feel inside (sniff) ... yeah, there's, or um, even though I express it, it's just kind of laughed at.

As we already stated, an Innovative Moment (IM) would by definition be an exception to this theme:

$\mathrm{L}:$...but then my feelings are my feelings and I'm entitled to them.

Identification of Innovative Moments. In order to allow raters to track what were IMs, within the client discourse, the sessions were, independently, coded in chronological 
order. When either therapist or client started to talk about any content that constituted an exception to the client's previously identified problematic self-narrative, raters identify the IM's onset and offset. The IMs contained both client and therapist dialogues, since from our perspective change is co-constructed between therapist and client (Angus, Levitt \& Hardtke, 1999). Thus, the IMs could result from questions or tasks suggested by the therapist, but they were only coded as IMs if the client accepts therapists' formulation and elaborates on them. For instance, if the therapist poses a question that contains an IM and the client denies it or does not elaborates it in some way it is not coded.

Categorization of one of the five types of IMs and definition of its salience. After identifying IMs, raters had to identify which type of IMs was present (e.g., action, reflection). In order to measure the degree of IM salience, when we use transcripts (instead of audio/video tapes), as in this study, we use the textual salience index defined as the percentage of words involved in the IM's elaboration. We computed for each client the following measures:

- Textual salience of each type of IM (e.g., action, reflection) for each session;

- Textual salience for overall IMs, independently of the type, for each session. This is a sum of the five types' salience.

- Mean textual salience for the entire treatment, per type and overall IMs.

In the results section findings from IMs are always referring to measures of textual salience.

\section{Results}

\section{Can IMCS reliably identify IM types in EFT therapy transcripts?}


Inter-rater agreement on IMs' textual salience was calculated as the overlapping words identified by both raters (rater 1 and 2) divided by the total amount of words identified by either rater. The percentage of agreement on overall IMs textual salience was $88.7 \%$.

For studying inter-agreement on IMs' type we used Cohen's Kappa, which in this sample was of .86, showing a strong agreement between raters (Hill \& Lambert, 2004).

2. Do good outcome cases present higher IMs' overall salience than poor outcome cases, as it occurred in Narrative Therapy?

In order to assure the homogeneity of the groups we analyzed the differences between the two groups regarding the number of sessions and the scores of BDI at the pre-test. No significant differences between the good and poor outcome cases were found for number of sessions. The level of symptom severity on the pre-test BDI was significantly different between the two outcome groups $(U=-1.96, \mathrm{p}=.050)$, with good outcome clients presenting significantly higher (more severity) BDI scores than poor outcome clients.

To test the differences between the two outcome groups in terms of the overall textual salience of IMs (see Figure 2), a Mann-Whitney $U$ test was carried out. There was a significant difference between good and poor outcome clients in IMs ( $U=-1.96$, $\mathrm{p}=.050$ ), with the good group evidencing higher levels of IMs' textual salience. Good outcome group had a mean of textual salience of IMs of $30.31(\mathrm{SD}=4.02)$ and pooroutcome group had a mean of $8.91(\mathrm{SD}=5.97)$.Specifically, this means that good outcome cases, as average, spent $30.3 \%$ of the sessions transcripts elaborating IMs, while poor outcome cases only spent a mean of $8.9 \%$.

3. Do re-conceptualization and performing change IMs distinguish good from poor outcome cases, as it occurred in Narrative Therapy? 
Good outcome clients were found to have significantly higher re-conceptualization $(U=-1.96, \mathrm{p}=.050)$ and performing change $(U=-2.09, \mathrm{p}=.037)$ IMs than the poor outcome clients. There was no significant differences between good and poor outcome groups on action $(U=-.22, \mathrm{p}=.83)$, reflection $(U=-1.53, \mathrm{p}=.13)$ and protest $(U=-1.09$, $\mathrm{p}=.28)$ IMs.

\section{Does the pattern of evolution of re-conceptualization and performing change}

IMs, across sessions, support the heuristic model of change?

Since re-conceptualization and performing change were the IM's types revealing differences between groups we have considered, for each group, a non-parametric smooth to summarize the trend of the response variable as a function of treatment session. Figure 3 shows the evolution of re-conceptualization IMs in good and poor outcome cases and figure 4 shows the evolution of performing change IMs in good outcome cases (performing change is absent in poor outcome cases). The black solid line in the plot represents the non-parametric smooth spline of the observed data (Keele, 2008) with respective $95 \%$ confidence intervals, within each outcome group. The advantage of such smoother is that we do not have to impose any rigid form for such function. The non-parametric smoothing spline emerges as a solution of an optimization problem, of minimizing simultaneously the residual sum of squares and second derivative of such a function (Hastie \& Tibshirani, 1990). Clearly, the evolution of both IMs reflects an increasing profile.

\section{Discussion}

These findings suggest that IMCS can reliably identify the different IMs types in EFT therapy transcripts, and may be used as an effective method for the identification and tracking of client narrative change. Thus, IMCS allows studying change in EFT, in 
which the concept of IM does not play a central role among the assumptions and techniques that guide the therapist. Furthermore, the emergence and development of IMs globally replicates the findings from NT (Matos et al., 2009), corroborating the heuristic model of change summarized previously.

Overall textual salience of IMs is higher in good outcome cases, suggesting that the increased narrative elaboration of IMs may be associated with therapeutic change. With low action, almost no re-conceptualization and absence of performing change IMs, poor outcome cases have almost only reflection and protest IMs throughout therapy. On the contrary, in good outcome cases all the IMs are present. Moreover, good outcome cases have a significantly higher elaboration of re-conceptualization and performing change IMs, as reflected in the increased textual salience. These types of IMs have also a clearly increasing trend in good outcome cases (unlikely poor outcome cases in which the trend is stable), as evidenced by the smoothing spline analysis. These differences between groups, in overall IMs and in re-conceptualization and performing change, replicates the findings of the narrative sample (Matos et al., 2009) as well as the ones from several cases studies (Gonçalves, Mendes, et al., in press; Ribeiro et al., in press), also being congruent with the model of narrative change previously presented, as far as the importance of re-conceptualization and performing change IMs in therapeutic change is concerned. It seems that re-conceptualization and performing change IMs play a critical in successful emotion-focused therapy for depression. We speculate that with the emergence of re-conceptualization the client is engaged in a self-empowered position that provides the scaffolding of the client's authoring of his or her new selfnarrative. The emergence of re-conceptualization IMs unfold the client sense of authorship, emphasizing that a new narrative of the self is developing. In the introductory section several hypothetical reasons were advanced on why re- 
conceptualization might be a core IM in successful therapy, such as being an IM that 1) articulates past with present, allowing for an integration of the problematic narrative into a new self-narrative; 2) positions the client as an author of his or her own experience; and 3) allows for the organization of the more elementary types of IMs (action, reflection and protest) (Gonçalves et al., 2009; Matos et al., 2009). The narrative model of change summarized in the introduction suggests that performing change IMs may be an extension into the future of the change present in reconceptualization IMs. Clearly, the reasons why re-conceptualization seems so vital in the change process need to be deeply analyzed with different methodological approaches (e.g., task analysis), but this study confirms once again its centrality in the change process, along with performing change IMs (see Matos et al., 2009 for a discussion on the importance of re-conceptualization IMs and its relation with other concepts, as insight or meta-cognitive functions).

One important difference from the pattern of IMs found in NT (Matos et al. , 2009) is the low presence of action IMs, not only in poor outcome, as well in good outcome cases. Also, although performing change is significantly higher in the good outcome group, and completely absent in the poor outcome group, it is almost half of what was found in the NT sample (EFT - 1.72\%; NT; 3.34\%). Previous research (Santos et al., 2009) has suggested that the 5 types of IMs clustered around two dimensions: one of action (action and performing change IMs) and one of meaning (reflection, protest, and re-conceptualization IMs). Thus, the results found in EFT, although globally replicating the results found in NT, suggest that EF therapists and clients privilege the meaning side of innovation's production. This finding is congruent with the assumptions of EFT (Greenberg \& Watson, 2006), that favours the emotional experiencing and elaboration instead of promoting innovative actions, outside the therapeutic setting. 
These results, thus, suggest that the main pattern of results in NT and EFT is similar: higher IMs elaboration in good outcome cases, higher re-conceptualization and performing change in good outcome cases. However, the IMs coding system also seems to capture some specificities of the therapeutic model: lower action and performing change when compared with NT. From these results, we speculate that the IMCS captures central similarities between the two therapies, as well some more superficial differences. Future research with other therapeutic models will inform us if theses similarities persist and if other specificities of different therapeutic models emerge with IMCS studies.

Since therapists, despite their theoretical background, search for novelties in the reconstruction of their clients problematic experiences, the replication of the data from NT (Matos, at al., 2009) is not a complete surprise, although EF therapists are focused in several dimensions of clients' lives other than unique outcomes (or IMs), which are clearly an important target for narrative therapists. For an EF therapist, emotional processing is much more important than identifying and expanding exceptions to the problematic self-narrative. However it seems that this elaboration of the emotional experience reflects closely what occurs in NT, in terms of IMs development. In this sense, we may hypothesize that engagement in experiential therapeutic interventions in EFT facilitates clients' emotional processing and, through this, may foster the development of IMs. Along these lines, we are suggesting that the elaboration of IMs could be the outcome of diverse therapeutic activities, from narrative questioning (White \& Epston, 1990; White, 2007) to experiential therapeutic strategies, like chair work (Elliott, Watson, Goldman, \& Greenberg, 2004).

The size of the analyzed sample is one of the major limitations of the present study making its conclusions limited and exploratory. However this study demonstrates the 
applicability of IMCS to a different therapeutic model and a different sample of clients. Another limitation is the difference found between poor and good outcome cases in the pre-test BDI, as some of the change in BDI scores could be explained by a regression to the mean (Cook \& Campbell, 1979). However the differences in the scores and the RCI (see Jacobson \& Truax, 1991; McGlinchey, Atkins, \& Jacobson, 2002) do suggest that these changes were in fact clinically meaningful.

Finally, at this point of our research program we cannot be sure that IMs are mediating variables of change. They can be outcome variables, and if so, there would be a kind of circularity in these results: good outcome cases (as assessed by the BDI) have a higher presence of IMs (another form of in-session outcome assessment). Other research designs are needed to test if IMs are mediating variables or outcome variables (see Kendall, Holmbeck, \& Verduin, 2004). However, as we argued before (Matos et al., 2009) even if IMs are outcome variables they could be a useful tool to study how intermediate outcomes develop within therapeutic sessions.

Future research with the IMCS can have important clinical implications, showing how therapists elicit and sustain the elaboration of IMs in good outcome cases and fail to do so in unsuccessful therapy. 


\section{References}

Angus, L., \& McLeod, J. (Eds.) (2004). The handbook of narrative psychotherapy: Practice, theory and research. London: Sage.

Angus, L., Levitt H., \& Hardtke, K. (1999). The narrative processes coding system: Research applications and implications for psychotherapy practice. Journal of Clinical Psychology, 55, 1255-1270.

Baerger, D. R., \& McAdams, D. (1999). Life story coherence and its relation to psychological well-being. Narrative Inquiry, 9, 69-96.

Beck, A. T., Steer, R. A., \& Garbin, M. G. (1988). Psychometric properties of the Beck Depression Inventory: Twenty-five years of evaluation. Clinical Psychology Review, 8, 77-100.

Beck, A. T., Ward, C. H., Mendelson, M., Mock, J., \& Erbaugh, J. (1961). An inventory for measuring depression. Archives of General Psychiatry, 4, 561-571.

Cook, T. D., \& Campbell, D. T. (1979). Quasi-experimentation: Design and analysis issues for field settings. Boston, MA: Houghton Mifflin Company.

Dimaggio, G. (2006). Disorganized narratives in clinical practice. Journal of Constructivist Psychology, 19, 103-108.

Elliott, R., Watson, J. C., Goldman, R., \& Greenberg, L. S. (2004). Learning emotionfocused therapy: the process-experiential approach to change. Washington, DC: American Psychological Association.

Gendlin, E. T. (1981). Focusing (2 $2^{\text {nd }}$ ed). New York: Bantam Books.

Gonçalves, M. M., Matos, M., \& Santos, A. (2009). Narrative therapy and the nature of "innovative moments" in the construction of change. Journal of Constructivist Psychology, 22, 1-23. 
Gonçalves, M. M., Matos, M., Salgado, J., Santos, A., Mendes, I., Ribeiro, A., Cunha, C., \& Gonçalves, J. (in press). Innovations in psychotherapy: Tracking the narrative construction of change. In J. D. Raskin, S. K. Bridges, \& R. Neimeyer (Eds.), Studies in meaning 4: Constructivist Perspectives on Theory, Practice, and Social Justice. New York: Pace University Press.

Gonçalves, M. M., Mendes, I., Ribeiro, A., Angus, L., \& Greenberg, L. (in press). Innovative moments and change in emotional focused therapy: The case of Lisa. Journal of Constructivist Psychology.

Gonçalves, M. M., Ribeiro, A., Matos, M., Santos, A., \& Mendes, I. (in press). The Innovative Moments Coding System: A new coding procedure for tracking changes in psychotherapy. In S. Salvatore, J. Valsiner, S. Strout, \& J. Clegg (Eds.), YIS: Yearbook of Idiographic Science - Volume 2. Rome: Firera Publishing Group.

Greenberg, L. S. (1986). Change Process Research. Journal of Consulting and Clinical Psychology, 54, 4-9.

Greenberg, L. S., \& Angus, L. E. (1994) How therapy works. Social Sciences and Humanities Standard Research Grant.

Greenberg, L. S., \& Watson, J. (1998). Experiential therapy of depression: Differential effects of client-centred relationship conditions and process interventions. Psychotherapy Research, 8, 210-224.

Greenberg, L. S., \& Watson, J. C. (2006). Emotion-Focused Therapy for Depression. Washington: American Psychological Association.

Greenberg, L. S., Rice, L. N., \& Elliott, R. (1993). Facilitating Emotional Change: The Moment-by-Moment Process. New York: The Guilford Press. 
Hastie, T. \& Tibshirani, R. (1990). Generalized additive models, Volume 43 of Monographs on statistics and applied probability. London: Chapman \& Hall.

Hill, C. E., \& Lambert, M. J. (2004). Methodological issues in studying psychotherapy processes and outcomes. In M. J. Lambert, (Ed.), Bergin and Garfield's Handbook of psychotherapy and behavior change (5 $5^{\text {th }}$ Ed.) (pp. $\left.84-135\right)$. New York: John Wiley \& Sons, Inc.

Honos-Webb, L., Stiles, W. B., \& Greenberg, L. S. (2003). A method of rating assimilation in psychotherapy based on markers of change. Journal of Counseling Psychology, 50, 189-198.

Honos-Webb, L., Stiles, W. B., Greenberg, L. S., \& Goldman, R. (1998). Assimilation analysis of Process-Experiential Psychotherapy: A comparison of two cases. Psychotherapy Research, 8, 264-286.

Honos-Webb, L., Surko, M., Stiles, W. B., \& Greenberg, L. S. (1999). Assimilation of voices in psychotherapy: The case of Jan. Journal of Counseling Psychology, 46, $448-460$.

Jacobson, N.S., \& Truax, P. (1991). Clinical significance: A statistical approach to defining meaningful change in psychotherapy research. Journal of Consulting and Clinical Psychology, 59, 12-19.

Keele, L. (2008). Semiparametric regression for the social sciences. New York: John Wiley and Sons.

Keevallik, S., \& Soomere, T. (2008). Shifts in early spring wind regime in North-East Europe (1955-2007). Climate of the Past, 4, 147-152.

Kendall, P., \& Holmbeck, G., \& Verduin, T. (2004).Methodology, design, and evaluation in psychotherapy research In M. J. Lambert (Eds), Bergin and 
Garfield's handbook of psychotherapy and behavior change (5th ed.) (pp. 16-43) New York: John Wiley \& Sons.

Matos, M., Santos, A., Gonçalves, M. M., \& Martins, C. (2009). Innovative moments and change in narrative therapy. Psychotherapy Research, 19, 68-80.

McAdams, D. P. (1993). The stories we live by: Personal myths and the making of the self. New York: William Morrow.

McGlinchey, J.B., Atkins, D.C., \& Jacobson, N.S. (2002). Clinical significance methods: Which one to use and how useful are they? Behavior Therapy, 33, 529550.

Ribeiro, A.P., Gonçalves, M. M., \& Ribeiro, E. (2009). Processos narrativos de mudança em psicoterapia: Estudo de um caso de sucesso de terapia constructivista [Narrative change processes in psychotherapy: A case-study of successful constructivist therapy]. Psychologica, 50, 181-203.

Santos, A., Gonçalves, M. M., \& Matos, M. (in press 2010). Innovative Moments and Poor-outcome in Narrative Therapy. Counselling and Psychotherapy Research. DOI: $10.1080 / 14733140903398153$

Santos, A., Gonçalves, M., Matos, M., \& Salvatore, S. (2009). Innovative moments and change pathways: A good outcome case of narrative therapy. Psychology and Psychotherapy: Theory, Research and Practice, 82, 449-466.

Sarbin, T. R. (1986). The narrative and the root metaphor for psychology. In T. R.

Sarbin (Ed.), Narrative psychology: The storied nature of human conduct (pp. 321). New York: Praeger.

The Case of Lisa [Special Section] (2008). Psychotherapy Research, 18 (6).

White, M. (2007). Maps of narrative practice. New York: Norton. 
White, M., \& Epston, D. (1990). Narrative means to therapeutic ends. New York: Norton. 
Table 1

IMs with examples

\begin{tabular}{lll}
\hline & Contents & $\begin{array}{l}\text { Examples } \\
\text { (Problematic narrative: depression) }\end{array}$ \\
\hline$\bullet$ & New coping behaviors facing anticipated or existent obstacles; & $\begin{array}{l}\text { C: Yesterday, I went to the cinema for the first time in } \\
\text { months! }\end{array}$ \\
\hline & Effective resolution of unsolved problem(s); & \\
\hline & - & \\
\hline
\end{tabular}

\section{Creating distance from the problem(s)}

- Comprehension - Reconsidering problem(s)' causes and/or awareness of its effects;

- New problem(s) formulations;

- $\quad$ Adaptive self instructions and thoughts;

- Intention to fight problem(s)' demands, references of self-worth and/or feelings of well-being.

\section{Centered on the change}

- Therapeutic Process - Reflecting about the therapeutic process;

- Change Process - Considering the process and strategies; implemented to overcome the problem(s); references of self-worth and/or feelings of well-being (as consequences of change);

- New positions - references to new/emergent identity versions in face of the problem(s).

\section{Criticizing the problem(s)}

\section{产 \\ - Repositioning oneself towards the problem(s). \\ Emergence of new positions}

- Positions of assertiveness and empowerment;

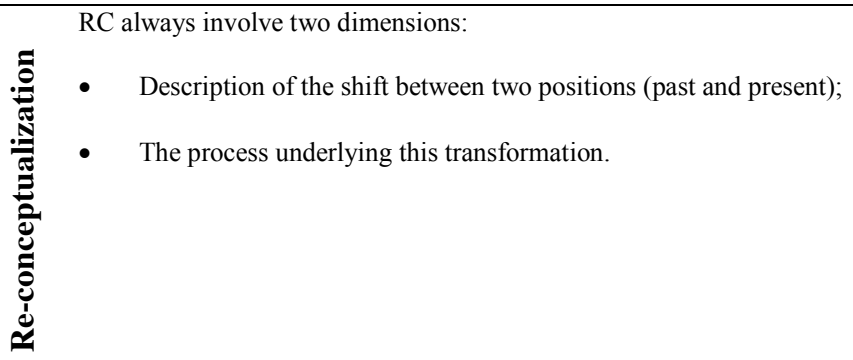

C: I realize that what I was doing was just, not humanly possible because I was pushing myself and I never allowed myself any free time, uh, to myself ... and it's more natural and more healthy to let some of these extra activities go...

C: I believe that our talks, our sessions, have proven fruitful, felt like going back a bit to old times, it was good, I felt good, I felt it was worth it.
C: What am I becoming after all? Is this where I'll be getting to? Am I going to stagnate here!?

C: I am an adult and I am responsible for my life, and, and, I want to acknowledge these feelings and I'm going to let them out! I want to experience life, I want to grow and it feels good to be in charge of my own life.

\author{
C: You know... when I was there at the museum, I \\ thought to myself: you really are different... A year ago \\ you wouldn't be able to go to the supermarket! Ever since \\ I started going out, I started feeling less depressed... it is \\ also related to our conversations and changing jobs... \\ T: How did you have this idea of going to the museum? \\ C: I called my dad and told him: we're going out today! \\ $\mathrm{T}$ : This is new, isn't it? \\ C: Yes, it's like I tell you... I sense that I'm different...
}


- Generalization into the future and other life dimensions of good outcomes;

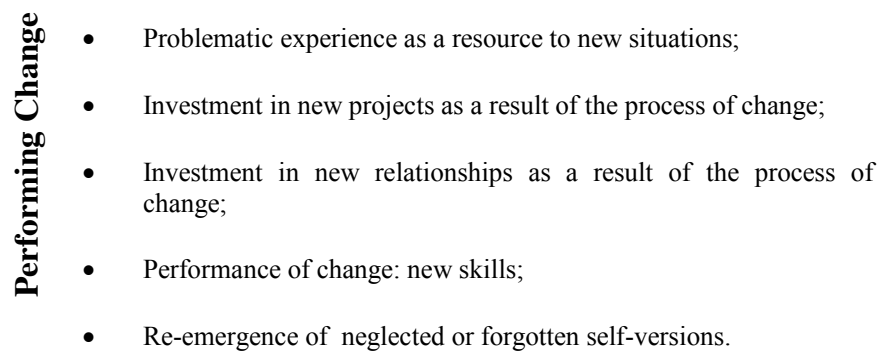

T: You seem to have so many projects for the future now!

$\mathrm{C}$ : Yes, you're right. I want to do all the things that were impossible for me to do while I was dominated by depression. I want to work again and to have the time to enjoy my life with my children. I want to have friends again. The loss of all the friendships of the past is something that still hurts me really deeply. I want to have friends again, to have people to talk to, to share experiences and to feel the complicity in my life again.

\section{Note. From The Innovative Moments Coding System: A coding procedure for tracking}

changes in psychotherapy, by M. M. Gonçalves, A. P. Ribeiro et al., in press. Adapted with permission. 


\section{Figure Captions}

Figure 1. Innovative moments' heuristic model of change in psychotherapy drawn from Narrative Therapy

Figure 2. Innovative moments in good and poor outcome groups

Figure 3. Evolution of re-conceptualization IMs in good and poor outcome cases

Figure 4. Evolution of performing change IMs in good outcome cases. 
Figure 1

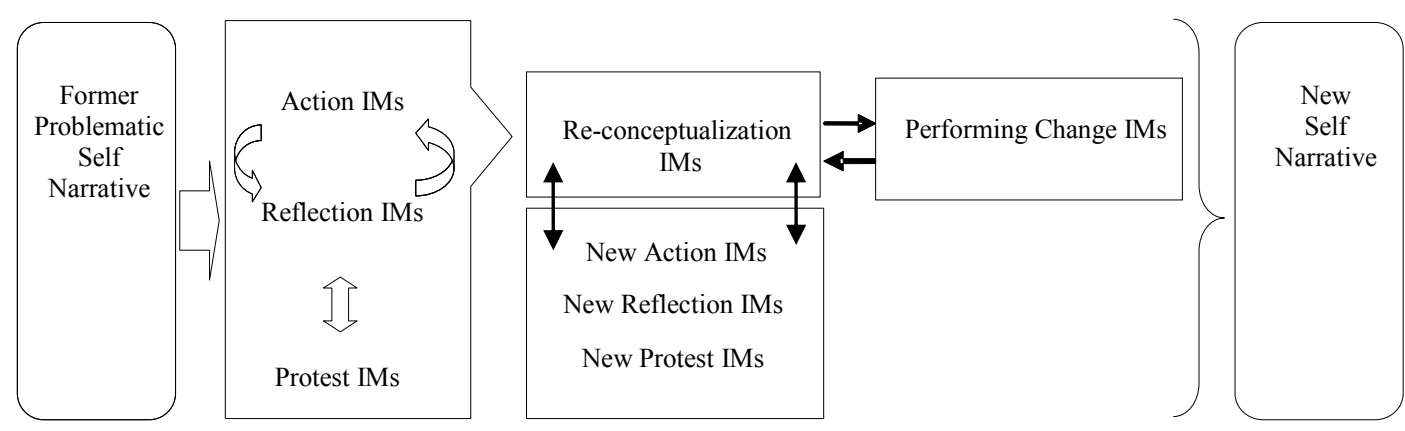

Therapy evolution 
Figure 2

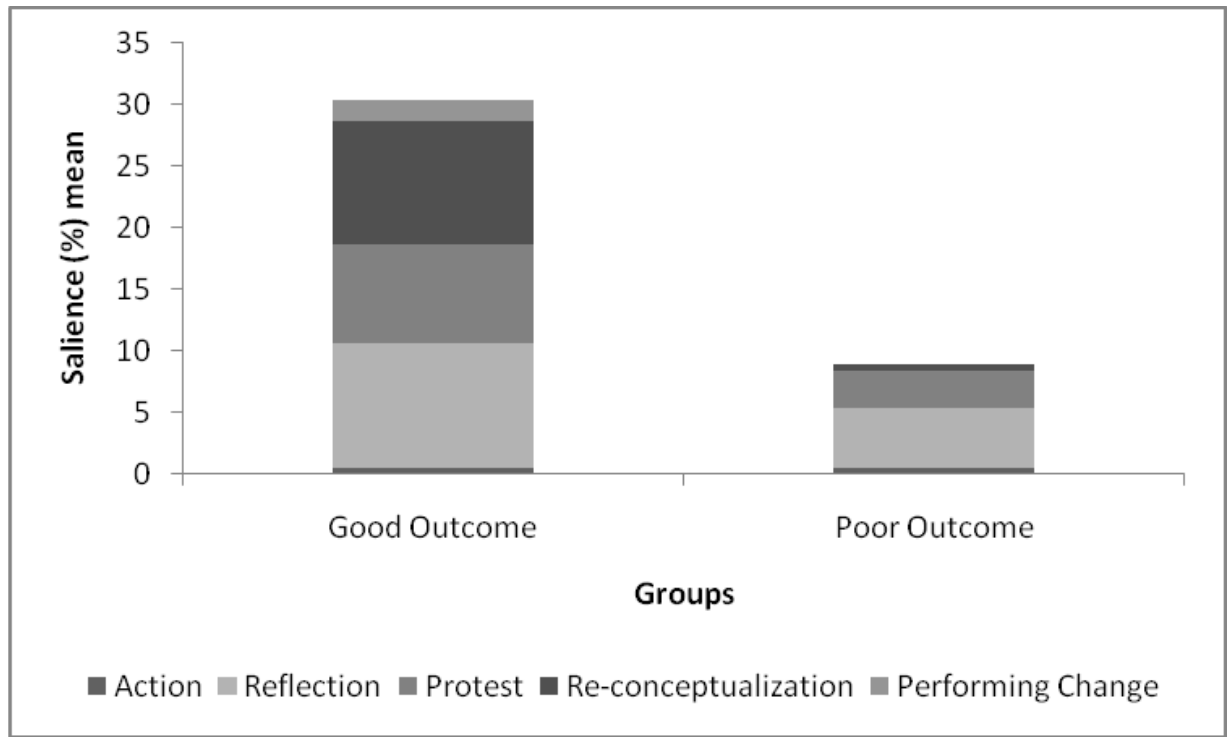


Figure 3
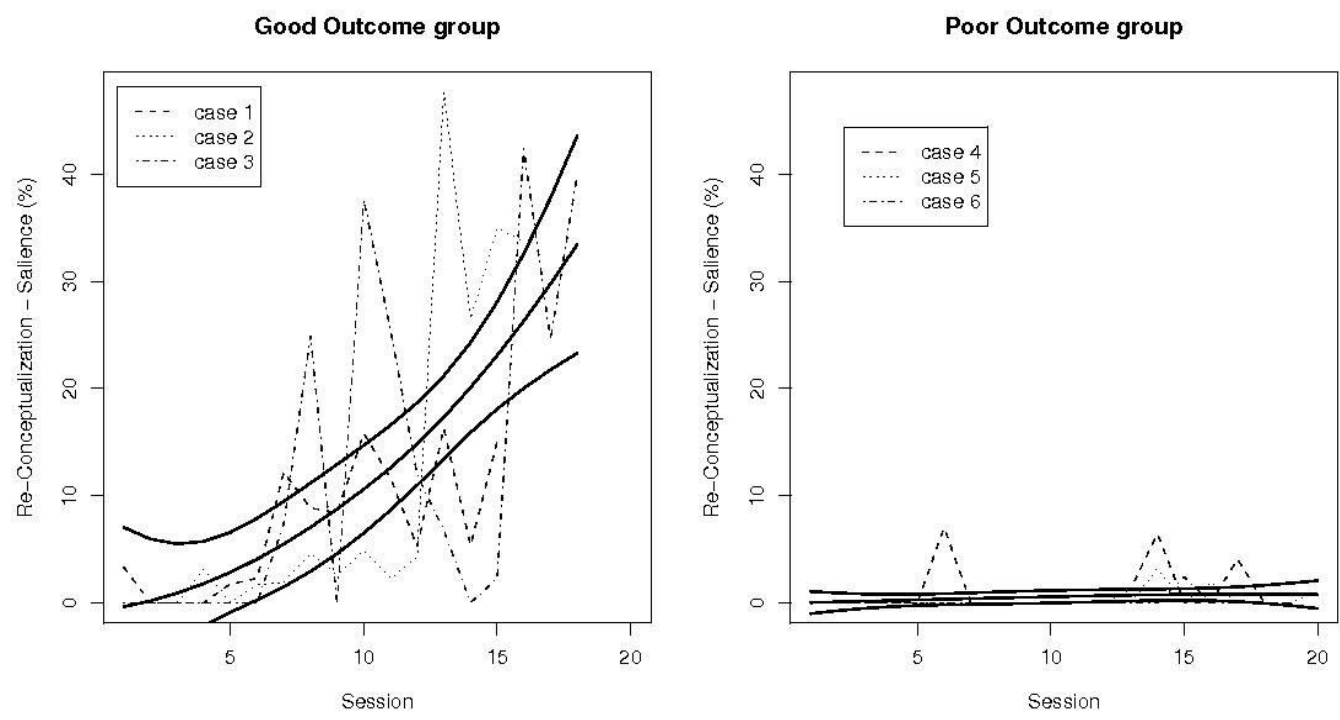
Figure 4

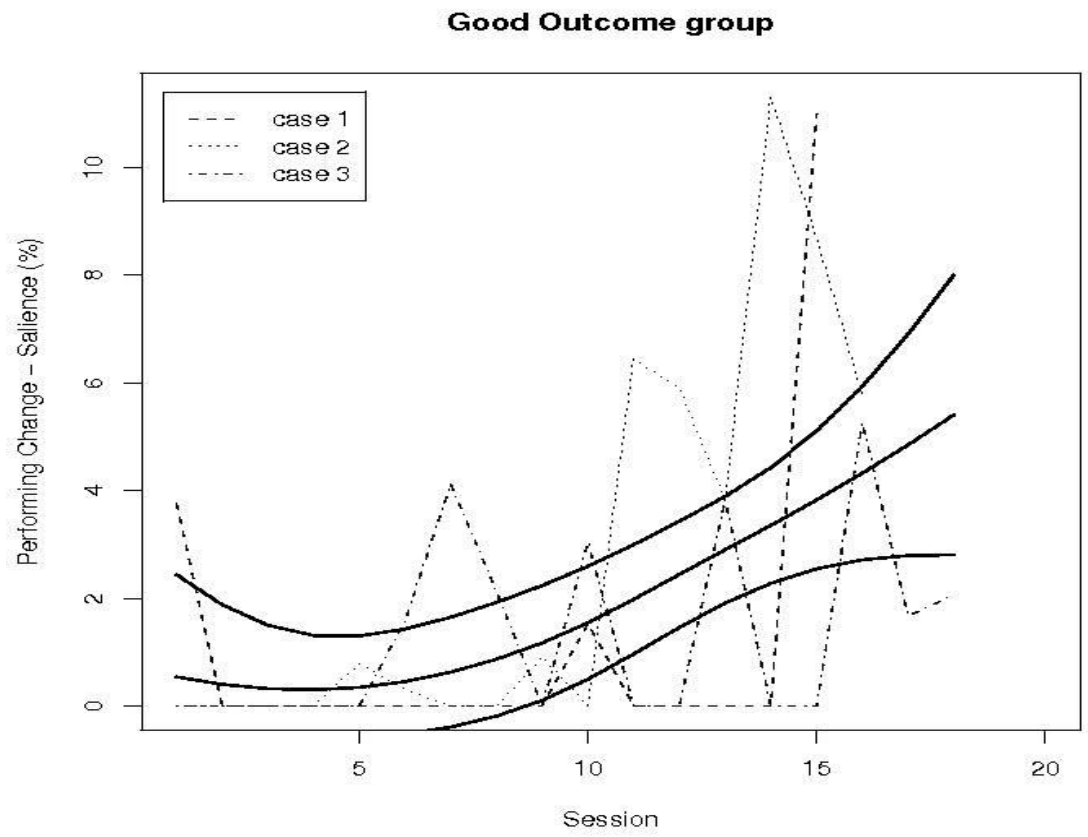


Narrative Change in Emotion-Focused Therapy 31 